Since the last report, not an unfavourable symptom has occurred, but the man has continued gradually to improve. It is indeed singular how little constitutional derangement has been produced by so severe an operation.-Guy's Hospital Reports.

ON THE

\section{UTILITY OF THE BRANCHES}

\section{OF THE}

\section{PROVINCIAL MEDICAL AND SURGICAL ASSOCIATION.}

[Read to the Shropslire and North Wales Branch at their Third Anniversary Meeting.]

By THOMAS JEFFREYS, M.D. OF LIVERPOOL.

Gentlemen,-As far as my experience goes, perhaps you will permit me to make a few remarks, upon the leading features and practical utility of the branches of the association, which now amount to six or seven throughout the kingdom, which I am more especially induced to do, because $I$ am inclined to think that imperfect ideas are entertained upon the main objects of them.

1st. I conceive that they are intended only as auxiliaries to the parent association.

$2 \mathrm{~d}$. To afford those members an opportunity of visiting the branches, who may find it totally impossible to attend the general anniversary meetings.

3rd. To supply such local information as it would be difficult to obtain in any other way.

Upon each of these points may I request your attention?

First, then, we all well know that in every rural district there are medical gentlemen who are not only valuable members of society, but also able practitioners, who, from the very nature of their occupations, cannot be supposed to have either time or the habit of making known to the world the results of their professional labours and observations; but if they were collected and conveyed to the president, secretaries, and central council of the branch, they may be skilfully digested, condensed, and arranged, so as to form an interesting report, essay, or address, to be read by the president upon his retiring from his office. This would always secure a valuable annual communication, without being an onerous task upon distant members, and be no great labour to those who are well known to have the power of composition and facility of production, such as the Shropshire and North Wales Branch can boast of, and would tend to heighten the standing of the medical profession who are members of the branch.

Secondly.-.'The great anniversary meeting of the association being, from necessity, sometimes held at very distant extremes of the kingdom, they can only be regularly attended by the more zealous members, and those within reasonable distance of that locality, and some, perhaps, of the latter are only known to each other by name, which is an evil these annual local gatherings have a tendency to remove: for it is always advantageous, both in a professional as well as in a friendly point of view, to encourage both information and good feeling upon all occasions, and in all pursuits and stations in society; but in none is it more desirable, because it is least thought of, than among medical men ; who sometimes, I fear, think they exalt themselves, by depreciating the well-earned merit of others. There also may be-some gratification afforded by looking forward for one welcome day of relaxation from the daily cares of a laborious and anxious profession.

Thirdly.- In the community of every district, town, and village, where medical men reside, there is always some leading feature which regulates the habits and forms the characters of medical men; and these are often so opposite, that it may seem incredible to those who have not thought upon the subject; for it is evident, that although this great discrepancy exists, we only differ in degree, and have all but one common object in view; therefore it is of some importance that this should universally be understood not only by medical men themselves, but by the community at large, which I am confident is not the fact, either in the one instance or the other. The exalted practitioner, who is favoured perhaps by fortune as well as merit, and exercises his skill amongst the aristocracy of the land, has no idea of the labour and fatigue of a rural practitioner, who is generally ill paid, if paid at all, and, in some extreme cases, is compelled to traverse his daily rounds on foot. On the other hand, the fashionable physician thinks little, if he should even be aware of the fatigues his junior brethren are exposed to in the conscientious discharge of public duties in large and densely-crowded commercial towns, where his daily visits may occasionally occupy from five to seven hours of his time, and his attention be called to fifty or sixty patients within that time, so that when the hour's of labour are over, instead of enjoying a quiet repast, he may find bodily repose more desirable than a refreshing meal; and such was often the case with the individual who now addresses you.

Such persons, you may easily suppose, could not very conveniently attempt anything much beyond an annual visit to the branches; although they may have useful facts to convey indirectly, not unworthy of the most enlightened and accomplished men in the medical profession. Again, I would ask, is it possible for a statesman to know the bearings of any legislative measure, unless he is possessed of a knowledge of his subject in detail ? and how is the enlightened physician or surgeon to know and convey that knowledge, unless he obtains it from those who frequent the haunts of disease, where its ravages are so often met with in an aggravated form, in dwellings where poverty and want are added to miserable suffering. This information, the branches of the Provincial Medical and Surgical Association are, I am confident, well calculated to afford, and may be converted into most important and extensive results. These branch meetings I then compare to the constant firing of small arms under the cover of greater guns, which we know are both essentially necessary to overcome a welldefended fortress, but which such reiterated attacks 
will silence, if not subdue, the most powerful ramparts.

I am inclined to think that one of the greatest errors which we in the Newton Branch have committed, is that of expecting, if not attempting, more than was practicable; and when a project fails from over-zeal, it runs a great risk of being abandoned altogether; and then men shelter themselves under the phrase, of its not being sufficiently scientific, or the time allotted for such communications being too limited for any useful purpose; but I say, the great evil has been, that of expecting or attempting too much at first; when it is well known, that if we do not overload ourselves in the first efforts, a heavy burthen may from habit and time be made comparatively light. In proof of this, I may add, that a very laudable attempthas this last year been made to collect a statistical arrangement of diseases, to form a report from the Newton branch district, from which good results were anticipated, on account of our very extensive charitable institutions, and also of ample resources from rural practitioners; and circulars were issued to obtain returns agreeably to Mr. Farr's well-known classification, or, if they preferred it, for private practice, "a certain ratio upon a given number of the total number of cases;" as, for instance, for every 1000, 10 may be noted; but there was a sad lack of energy in the returns, and this I imputefirst, to that of Mr. Farr's plan being too complicated without some labour and study, and that of the ratio of 10 in every $1000, \mathrm{I}$ am quite sure, not being understood. We, however, still contemplate, and hope, that a modification of it, more simple, may produce some fruits.

For the last 30 years of my life, I have been in the constant habit of keeping an exact register of every patient's name, residence, sex, age, duration, and termination of the disease, all comprised in one line, as well as an history and extended notes of almost every case which has come under my care; with regular indexes to each volume, enabling me to refer in ten minutes to the number of each separate disease during that period, and which has been kept for my own private satisfaction, and without the prospect of going beyond it. Perhaps, however, it may not be unacceptable to this meeting, to know that I have found a great difference in the increased number of females in public practice, as compared with those in private, which may possibly be accidental. The proportion in public I find to be in excess about 290 in the thousand, but in private do not exceed more than about 90 in every 1000 . This, however, ought not to be brought forward as correct data for a statistical report, unless it was balanced by those who have been engaged in the practice of midwifery, surgery, and diseases of children, more than I have, of late years ; it may, however, serve to show, that some well-digested plan for each branch of the association to adopt, may lead to useful if not valuable materials to build upon for national information.

There are also many other points which may be noted, without being offensive to individuals, who may feel themselves aggrieved from any irregularities, which they themselves may feel unable to cope with, but which may have the advantage of a decision from their more experienced brethren.

The mode of remuneration, likewise, may form a useful subject for discussion and arrangement, and may have been of important practical benefit under the late Vaccination Act.

Indeed, I could state many other points from which benefit would accrue by a union and comparison of ideas amongst medical men; but as these will present themselves, should the path of inqu iry be opened, I will not weary your attention by extending these remarks.

\section{EFFECTS OF PRAYER AND CAYENNE PEPPER ON}

\section{INFLAMMATION OF THE BOWELS.}

Yesterday a lengthened investigation was gone into before Mr. Baker, the coroner, at the Royal Oak, Galway-street, St. Luke's, on the body of Elizabeth Morgan, aged 55 years, whose death was alleged to have been caused through improper treatment by unqualified persons.

Maria Walker, of 31, Cross-street, Islington, said she had known the deceased about twelve months. For some time past she had suffered from a spasmodic affection, and, on Tuesday week last, witness was sent for to attend her. Witness found her very ill, but no medical gentleman was called in, it being against the religious tenets of the sect to which the deceased belonged to do so. The sect to which she belonged styled themselves "The Church of Jesus Christ, and Latterday Saints," their place of meeting being in Castlestreet, Cow-cross. They dated their origin from the apostles, and treated their sick according to the following text, taken from the last chapter of the epistle of St. James: "Any illness amongst you, ye shall call for the elders of the church, and anoint yourselves with oil in the name of the Lord." She (witness) had known cases of healing under such circumstances, but the deceased sank, and died on Saturday last.

Mary Ann Albin, Spencer-place, Goswell-road, wife of one of the elders of this foolish sect, said she was called to see the deceased on Tuesday morning, and from her appearance thought she was suffering from inflammation of the bowels. No surgeon was sent for. Witness administered some "sage-tea with cayenne pepper" in it; leeches and other remedies were also applied. Every thing was prayed over before it was given.

The coroner said the remedy appeared to him to be worse than the disease, and he hardly knew how to deal with the case, as he had his doubts whether it was not one of manslaughter.

Mr. D. Lewis of Bunhill-row, surgeon, said he had attended the deceased on a former occasion for a spasmodic affection, and had not the least doubt that if he had been called in on the present occasion, he could have saved her life. He had seen the body since death, which he should attribute to mortification of the bowels. Although the cayenne pepper was not the cause of death, it was the worst thing that could be given to her.

The coroner said, in his opinion the case was not strong enough to warrant a verdict of manslanghter being returned; but he trusted the publiration of it in the papers would act as a caution to the members of this strange sect, and that they would see the necessity of calling in medical aid. 